\title{
Dimensionamento da 'economia política' na 'economia da saúde': para refletir sobre o conceito de sustentabilidade
}

\author{
Dimensioning of 'political economy' in 'health economics': reflecting \\ on the concept of sustainability
}

Daniel Figueiredo de Almeida Alves', Leonardo Carnut², Áquilas Mendes $\mathbf{3}, \mathbf{4}$

DOI: 10.1590/0103-11042019S513

1 Faculdade de Ciências Médicas da Santa Casa de São Paulo (FCMSCSP) São Paulo (SP), Brasil. d.fig94@gmail.com

2 Universidade Federal de São Paulo (Unifesp), Centro de Desenvolvimento de Ensino Superior em Saúde (Cedess) - São Paulo (SP), Brasil.

3 Universidade de São Paulo (USP), Faculdade de Saúde Pública - São Paulo (SP), Brasil.

4 Pontifícia Universidade Católica de São Paulo (PUC-SP), Programa de Estudos Pós-Graduados em Economia Política - São Paulo (SP), Brasil.
RESUMO Este artigo teve como objetivo mapear a produção da economia da saúde no Brasil e seus principais temas, destacando a relevância da economia política, com o intuito de refletir sobre a sustentabilidade do Sistema Único de Saúde. Para tanto, realizou-se uma pesquisa quantitativa exploratória, por meio de coleta de dados nos currículos de pesquisadores doutores em economia da saúde na Plataforma Lattes (CNPq) em 2018. Recuperaram-se os pesquisadores por meio do termo 'economia da saúde' e 'economia política'. Classificaram-se suas produções nas áreas temáticas de 'financiamento', 'política de saúde’, 'gestão em saúde', 'análise de custo-efetividade'. Identificaram-se 471 currículos de doutores associados ao termo 'economia da saúde', dos quais 53,9\% (254) foram considerados 'economistas da saúde'. Entre os temas mais trabalhados, 42,5\% (108) enfatizam a 'análise de custo-efetividade', 20,9\% (53) salientam a 'gestão em saúde' e 20,5\% (52) ressaltam o 'financiamento'. Dos 254, apenas $11,0 \%$ (28) produzem em 'economia política'. A preponderância da produção em 'gestão em saúde' e 'análise de custo-efetividade' sugere que os pesquisadores da economia da saúde estão majoritariamente alinhados ao pensamento neoclássico. Além disso, a produção de conhecimento pelos paradigmas da 'economia política' é rarefeita.

PALAVRAS-CHAVE Economia da saúde. Sistemas de saúde. Saúde coletiva. Política de saúde. Financiamento da assistência à saúde.

ABSTRACT This article aims to map the production of health economics in Brazil and its main themes, highlighting the relevance of political economy, with the aim of reflecting on the sustainability of the Unified Health System (SUS). For that purpose, a quantitative exploratory research was carried out, through data collection in curricula of health economics researchers at the Plataforma Lattes (CNPq) in 2018. Researchers were retrieved through the term 'health economics' and 'political economy'. Their productions were classified in the thematic areas of 'financing', 'health policy', 'health management', 'cost-effectiveness analysis'. 471 curricula of doctors associated with the term 'health economics' were identified, of which 53.9\% (254) were considered 'health economists'. Among the most addressed topics, 42.5\% (108) focus on 'cost-effectiveness analysis', 20.9\% (53) on 'health management', and 20.5\% (52) on 'financing'. Of the 254, only $11.0 \%$ (28) show a production in 'political economy'. The preponderance of productions in 'health management' and 'costeffectiveness analysis' suggests that health economics researchers are mostly aligned with the neoclassical thinking. Moreover, the production of knowledge by the paradigms of 'political economy' is scarce.

KEYWORDS Health economy. Health systems. Public health. Health policy. Healthcare financiang. 


\section{Introdução}

Os sistemas de saúde têm tido que se adaptar às mudanças sociais bruscas, especialmente pelo fato das implicações políticas e econômicas vividas no cenário mundial neoliberal e de capitalismo financeirizado ${ }^{\mathbf{1}, 2}$. Como reflexo do movimento do capital em escala mundial, o Brasil tem vivido um cenário político de intensa inflexão que denota transformações substantivas no regime político ${ }^{3}$ e repercussões na capacidade dos sistemas locorregionais de saúde em responder às necessidades sanitárias, comprometendo, assim, sua sustentabilidade.

Em termos desenvolvimentistas, os sistemas de saúde são considerados 'sustentáveis' quando estes operam por um sistema organizacional com habilidade de longo prazo para mobilizar e alocar recursos suficientes e apropriados (trabalhadores, tecnologia, informação e finanças) para atividades que se direcionem às necessidades/demandas dos indivíduos e da saúde pública. Ainda que consideremos essa definição importante, ela dialoga mais com os determinantes econômicos que os políticos da sustentabilidade dos sistemas.

Mesmo tendo como parâmetro a definição supracitada, o conceito de 'sustentabilidade' não é consensual na literatura científica, por isso investigar em quais epistemes esse conceito está assentado parece ser um investimento intelectual profícuo para qualificar o debate. Nos termos da construção de uma economia política crítica da saúde, a preocupação reside em identificar quais as intencionalidades que subjazem à produção científica que se dedica ao estudo dos sistemas de saúde, descortinando a direção e o sentido da 'sustentabilidade' que investigam, entendendo que o econômico e o político não são autônomos.

A rigor, no mundo da pesquisa científica na economia da saúde, a perspectiva neoclássica de conceber o econômico é a hegemônica. Para essa perspectiva, a sustentabilidade está aliada à ideia de estratégia organizacional para orientar seus domínios e indicadores. Originalmente concebido para garantir a sobrevivência de empresas em um mercado cada vez mais competitivo ${ }^{4}$, não é de estranhar que a lógica incutida por esta produção também corresponda à perspectiva da sustentabilidade de mercado ${ }^{5}$.

No entanto, a economia política crítica da saúde está preocupada com outras implicações. O foco é a reflexão necessária e a repolitização do movimento sanitário no tocante ao aparelhamento do Estado sob a égide neoliberal, assim como os desafios no âmbito acadêmico em produzir conhecimento que dialogue com o real, tomando-se como ponto de origem a defesa do direito à saúde. Este, sim, é o conteúdo que esta perspectiva advoga à 'sustentabilidade', tendo como fundamento a manifestação material desse direito ${ }^{6}$, ou seja, a efetividade do direito, e não suas retóricas.

Assim, ao considerarmos a saúde no olhar da economia política crítica, devemos lembrar que ela não pode estar descolada da interpretação filosófica que considera o gênero humano essencialmente ligado à continua transformação da natureza para a satisfação de crescentes necessidades ${ }^{7}$, cuja saúde é uma delas. Em outras palavras, trata-se do modo de produção e reprodução desse ser social, cujo estudo da esfera produtiva não se esgota nela, mas é uma síntese de múltiplas determinações ${ }^{8}$.

Para se ter completude explicativa, portanto, não se deve utilizar uma epistemologia que desconsidere a inserção mundial dependente dos sistemas de saúde no mundo, alijando do debate a formação social desigual e combinada como a do Brasil por exemplo. Além disso, essa relação desigual reflete-se nas relações entre Estados Nacionais em plano internacional, por justamente interligarem-se via um mercado mundial em que a remessa dos lucros é drenada em direção aos países de capitalismo central ${ }^{9}$. Ou seja, considerar a epistemologia hegemônica sobre o econômico é um engodo teórico que se afasta da materialidade do direito à saúde e dificulta a compreensão da real sustentabilidade do sistema em países como Brasil.

Vale a pena lembrar que, em termos históricos, as forças produtivas latino-americanas apresentam especificidades particulares 
orientadas à lógica imperialista ${ }^{10}$. Em linhas gerais, esse caráter desigual e combinado condiciona uma lógica específica de acumulação capitalista, que tem como marca a coexistência de modernas relações de trabalho e os mais persistentes arcaísmos ${ }^{11}$. Essa mescla característica da formação sócio-histórica desse bloco econômico possibilita, curiosamente, o avanço do moderno sem necessariamente o desenvolvimento completo dessas forças ${ }^{\mathbf{1 2}}$. Dessa forma, a economia da saúde, ao considerar a perspectiva neoclássica hegemônica em seus estudos, desconsidera esses elementos em suas análises, por isso, em certa medida, estão ideologicamente aprofundando a dependência.

Outro aspecto essencial na análise da economia política crítica é considerar os interesses políticos das classes e suas frações no conjunto da análise. Assim, uma especificidade particular da classe dominante na América Latina, e principalmente no Brasil, é ter uma burguesia que não demonstra interesse no desenvolvimento das forças produtivas nacionais ${ }^{13}$. Isso tem toda uma implicação política para o desenvolvimento teórico sobre os conceitos referentes às análises econômicas empreendidas nos sistemas de saúde do sul global, sob a episteme neoclássica.

Quando se trata de investir nos sistemas de saúde para que eles operacionalizem o direito à saúde como 'acesso universal', a burguesia desse bloco econômico amedronta-se e teme mudanças sociais que envolvam os 'de baixo', costumeiramente recorrendo a conchavos e acordos políticos 'pelo alto' para manutenção da ordem dominante' ${ }^{\mathbf{1 3}}$. Em suma, esses elementos, na análise da economia da saúde convencional (neoclássica), inclusive a neodesenvolvimentista ${ }^{\mathbf{1 4}}$, geralmente são desconsiderados. Os cientistas filiados a essas perspectivas findam por produzir um conhecimento que reproduz as relações sociais capitalistas, não necessariamente traduzindo-se em melhores condições de vida e de trabalho para quem não tem capacidade de pagamento.

$\mathrm{Na}$ perspectiva da economia política crítica, a saúde é tida como uma 'necessidade radical'15, portanto, a rigor, a sustentabilidade da saúde não é possível em uma sociabilidade capitalista, só sendo possível em termos objetivos em outro modo de produção que considere extintas a alienação e a espoliação do trabalho ${ }^{\mathbf{1 6}}$. Enquanto esse momento histórico não acontece, resta à economia política crítica da saúde denunciar a quais interesses os conhecimentos hegemonicamente produzidos atendem, repolitizando o movimento sanitário e desmistificando o papel do direito burguês ${ }^{\mathbf{1 7}}$, mas reconhecendo a defesa do direito à saúde como o limite do possível.

Mais especificamente, a análise marxiana contida na crítica à economia política clássica e seus comentadores inauguram o entendimento que os níveis de saúde de uma população são determinados pelos seus condicionantes políticos e econômicos, e não somente pelo acesso à assistência à saúde ${ }^{\mathbf{1 8}}$. Essa crítica se contrapõe diretamente aos axiomas neoclássicos que insistem em permanecer no estreito entendimento da microeconomia - endereçando a problemática da saúde a resoluções de ordem meramente técnico-gerencial -, negando-se a enxergar a saúde na totalidade de suas relações sociais.

De todo modo, essa disputa político-ideológica é central para o entendimento das especificidades da questão da saúde no contexto brasileiro e seus desdobramentos no Sistema Único de Saúde (SUS). No cenário da crise do capitalismo contemporâneo, sob a égide do capital portador de juros, é observada a expressiva e crescente permissão do Estado à apropriação do fundo público, que intensifica o enfraquecimento do direito à saúde ${ }^{2,19}$. As políticas sociais, ordenadas pela visão hegemônica no interior do Estado capitalista - o pensamento neoclássico -, tornam-se impeditivas da consolidação de uma saúde pública e universal ${ }^{20}$.

Por esses motivos, reconsiderar o papel que a economia política crítica tem em reconectar a discussão dos objetos apropriados pelas ciências econômicas e reinseri-las no todo social é fundamental. Em especial a saúde, quando tomada como um objeto dessa economia, é refém de uma tendência à matematização de 
seus processos, demonstrando o quanto sua análise fica reduzida a maiores ou menores níveis de eficiência em função dos lucros e dividendos das empresas e de incorporação tecnológica no SUS ou, mais ainda, do setor privado contratado pelo sistema.

É nesse bojo que este estudo visa compreender como a produção do conhecimento em economia política da saúde vem-se edificando na tentativa de ser um contraponto à perspectiva neoclássica que hegemoniza a discussão no setor saúde. Assim, o objetivo deste estudo é mapear os pesquisadores que trabalham na área de economia da saúde no Brasil para discutir sobre o papel da 'economia política' na área e sua contribuição para o dissenso sobre o pensamento econômico e repensar o conhecimento que garanta a real sustentabilidade do sistema de saúde.

\section{Métodos}

Com o objetivo de mapear e promover uma aproximação do campo da economia da saúde no Brasil, e a presença da economia política no País, foi necessário identificar os pesquisadores atuantes e delimitar quais temáticas preferencialmente produzem. Para tanto, empregou-se uma análise de cunho quantitativo e exploratório para levantar hipóteses sobre a produção científica da economia da saúde, seus principais temas e como esta direciona a discussão sobre os sistemas de saúde. Foi utilizado como fonte da coleta de dados o currículo eletrônico disponibilizado na plataforma Lattes - requisito compulsório que todos os pesquisadores brasileiros devem preencher e atualizar no Ministério da Ciência e Tecnologia -, no período de outubro a novembro de 2018.

Com isso, foi desenhado um percurso metodológico que consiste em desvelar os níveis de aprofundamento dos economistas da saúde com as variáveis estudadas. Para isso, em primeiro lugar, foi importante delimitar quem são esses 'economistas da saúde'. Com esse intuito, realizou-se uma busca na plataforma
Lattes utilizando o termo (entre aspas) 'economia da saúde' e selecionando apenas currículos dos pesquisadores doutores. Optou-se por considerar apenas os pesquisadores doutores por dois motivos: o primeiro relacionado com o crescimento da área da economia da saúde, com cada vez mais adeptos, poderia aumentar substancialmente a quantidade currículos para recuperação e análise; e o segundo baseia-se nos argumentos do Conselho Nacional de Desenvolvimento Científico e Tecnológico (CNPq), que reconhece como pesquisadores independentes, pelo menos do ponto de vista de captação de recursos, apenas os pesquisadores doutores.

Após a aplicação desse primeiro filtro, somente foram considerados 'economistas da saúde' aqueles em que os currículos apresentavam o termo empregado ('economia da saúde') nas seguintes subdivisões do currículo: 'texto informado pelo autor', 'doutorado', 'linhas de pesquisa ativa' e 'artigos publicados em periódico científicos na área'. De maneira concomitante, nesses pesquisadores doutores considerados 'economistas da saúde', foi realizada uma busca utilizando o termo 'economia política'. Nesse momento, não foi empregado qualquer modalidade de filtro adicional. Com relação ao 'núcleo formativo', foram coletadas as graduações de nível superior e área de doutorado.

Em um segundo instante, foi classificada a produção dos artigos em periódicos científicos publicados pelos considerados 'economistas da saúde' nas subáreas 'financiamento', 'política de saúde', 'gestão em saúde' e 'análise/ avaliação de custo, efetividade e eficiência'. Essas subáreas foram escolhidas por serem consideradas as mais relevantes e sugerirem a filiação a certos paradigmas econômicos, conforme já descrito no estudo publicado pela Associação Brasileira de Economia da Saúde (Abres) ${ }^{21}$. Além disso, foi delimitado quais dos pesquisadores doutores também produzem artigos científicos em 'economia política' e 'economia política da saúde'. Assim, foi usada como critério de busca a menção direta do termo 'economia política' em artigos, publicações em revistas da área ou títulos sugerindo a 
relação entre as estruturas políticas e econômicas e análise do resumo/abstract dos artigos que preenchiam esses critérios - sendo estes considerados 'economistas políticos' dentro da economia da saúde.

Em um terceiro instante, foi realizada uma comparação entre os pesquisadores doutores que produzem artigos classificados na subárea 'análise/avaliação de custo, efetividade e eficiência' com aqueles que apresentam artigos publicados em 'economia política' e de quais áreas de doutorados são provenientes. A escolha desses dois tipos de produção é enfatizada devido à diferença substancial de filiação paradigmática entre os economistas que produzem na análise/avaliação de custo (predominantemente neoclássicos), daqueles que produzem na economia política (majoritariamente keynesianos e marxistas).

Dos pesquisadores doutores considerados 'economistas da saúde', foi identificado se suas produções científicas tinham algum alinhamento com a perspectiva da 'economia política' e da 'economia política da saúde'. O objetivo foi traçar tendências entre as subáreas da economia da saúde ('financiamento', 'política de saúde', 'gestão em saúde' e 'análise/avaliação de custo, efetividade e eficiência') comparando-as com o total dos economistas da saúde.

Em suma, esse percurso metodológico, subdividido em quatro momentos, permitiu comparar a economia da saúde com a economia política produzida dentro desse campo e, além disso, traçar paralelos importantes entre a produção científica e os núcleos formativos.

Apesar de este estudo ser uma primeira abordagem acerca do mapeamento do campo da economia política da saúde no Brasil, é pertinente demonstrar suas limitações. Utilizar exclusivamente dados quantitativos, dependendo da atualização dos currículos Lattes por parte dos pesquisadores, e não avaliar qualitativamente os artigos produzidos constituem-se limites deste estudo. Dessa forma, compreende-se que estudos qualitativos posteriores devem ser realizados para refinar essa análise. Contudo, mesmo com o caráter exploratório deste estudo, torna-se possível sustentar as elaborações realizadas a partir da perspectiva da economia política.

Outra limitação importante é considerar como 'pesquisadores' apenas aqueles que têm doutorado, haja vista que muitos trabalhadores do SUS realizam pesquisas e publicam no campo da economia da saúde e não têm esta titulação. Em alguns casos, mesmo que do ponto de vista formal, profissionais cujo maior título é a graduação, especialização ou mestrado possuem os requisitos formativos suficientemente compatíveis para configurar o componente científico de uma pesquisa. Além disso, é pertinente lembrar que o componente científico de uma pesquisa só pode ser constatado por meio da avaliação de seu conteúdo. Isso, por si só, denota a limitação em que este estudo deve ser lido e ajuda a justificar a necessidade de novos estudos que se dediquem a mapear os pesquisadores em outros níveis de titulação.

\section{Resultados}

Após a coleta dos currículos dos pesquisadores doutores, identificou-se, em uma busca 'simples' da plataforma Lattes, que 471 deles estavam associados ao termo 'economia da saúde'. Contudo, quando analisado o termo nas seções específicas do currículo ('texto informado pelo autor', 'doutorado', 'linhas de pesquisa ativa' e 'produção em artigos publicados em periódicos científicos'), foram identificados apenas 254 (53,93\%) 'economistas da saúde', o que se considerou como o total de pesquisadores doutores (100\%) que se dedicam cotidianamente ao desenvolvimento da 'economia da saúde' no Brasil (tabela 1). Essas seções foram consideradas importantes para uma análise mais apurada do esforço intelectual dos pesquisadores doutores na 'economia da saúde'.

Uma vez que os pesquisadores doutores, do campo em questão, foram delimitados, realizou-se uma busca em seus currículos 
com o termo 'economia política'; dessa vez, sem nenhuma modalidade de filtro, considerando apenas a presença do termo, ficando evidenciado que apenas 29,92\% (76) dos pesquisadores doutores se dedicam à economia política (tabela 1).

Tabela 1. Presença do termo 'economia da saúde'- nas seções especificadas - nos currículos dos pesquisadores extraídos a partir da plataforma Lattes e a presença do termo 'economia política' nos pesquisadores considerados economistas da saúde. Brasil, 2018

\begin{tabular}{lrr}
\hline Presença do termo 'economia da saúde' no currículo & N & $\%$ \\
\hline Não apresentavam o termo 'economia da saúde' nos seus currículos & 217 & 46,07 \\
Apresentavam o termo 'economia da saúde' nos seus currículos & 254 & 53,93 \\
Total & 471 & 100,00 \\
\hline Presença do termo 'economia política' no currículo & $\mathbf{N}$ & $\%$ \\
\hline Não apresentavam o termo 'economia política' nos seus currículos & 76 & 70,08 \\
Apresentavam o termo 'economia política' nos seus currículos & 254 & 29,92 \\
Total & 100,00 \\
\hline
\end{tabular}

Fonte: Elaboração própria baseada em dados do Currículo Lattes, 2018.

Com o intuito de aprofundar a descrição dos 'economistas da saúde', foi estudada a maneira com que se distribuíam em suas graduações primeira e segunda - e área de doutorado. $\mathrm{Na}$ primeira graduação, há o predomínio de dois cursos: Ciências Econômicas, 34,25\% (87), e Medicina, 26,38\% (67) (tabela 2). A maioria dos pesquisadores doutores não apresentava segunda graduação, 94,88\% (241) (tabela 2). No tocante ao doutorado, identificou-se a preponderância de três áreas: saúde coletiva/ saúde pública/medicina preventiva, 29,14\% (74); economia, 27,96\% (71); e ciências médicas, 9,84\% (25) (tabela 3).

Tabela 2. Primeira e segunda graduações informadas pelos pesquisadores nos Currículos Lattes recuperados a partir do descritor 'economia da saúde'. Brasil, 2018

\begin{tabular}{lrr}
\hline Primeira Graduação dos pesquisadores & N & $\%$ \\
\hline Ciências Econômicas & 87 & 34,25 \\
Medicina & 67 & 26,38 \\
Farmácia & 19 & 7,48 \\
Enfermagem & 16 & 6,30 \\
Administração & 9 & 3,55 \\
Odontologia & 6 & 2,36 \\
Ciências Contábeis & 5 & 1,97 \\
Matemática & 5 & 1,97 \\
Ciências Biológicas & 4 & 1,57 \\
Ciências Sociais & 4 & 1,57 \\
Outros & 42 & 12,60 \\
Total & 32 & 100,00 \\
\hline
\end{tabular}


Tabela 2. (cont.)

\begin{tabular}{lrr}
\hline Segunda Graduação dos pesquisadores & N & $\%$ \\
\hline Não apresentam segunda graduação & 241 & 94,88 \\
Ciências Econômicas & 5 & 1,97 \\
Direito & 3 & 1,18 \\
Outros $^{\star \star}$ & 5 & 1,97 \\
Total & 254 & 100,00 \\
\hline
\end{tabular}

Fonte: Elaboração própria baseada em dados do Currículo Lattes, 2018.

* Incluem as graduações: Engenharia Elétrica, História, Nutrição, Psicologia, Biomedicina, Engenharia Civil, Engenharia Química, Serviço Social, Ciências da Computação, Comunição Social, Direito, Educação Física, Engenharia Agronômica, Engenharia de Produção Mecânica, Estatística, Geologia e não apresenta gradução no currículo. ** Incluem as segundas graduações: Fisioterapia, Admnistração, Filosofia e Nutrição.

Tabela 3. Área do doutorado e estratificação da produção de artigos científicos na subárea de 'análise/avaliação de austos, afetividade e aficiência' e produção de artigos científicos em 'economia politica'por área de doutorado nos Currículos Lattes dos pesquisadores recuperados a partir do descritor 'economia da saúde'. Brasil, 2018

\begin{tabular}{|c|c|c|c|c|}
\hline \multicolumn{3}{|l|}{ Área do Doutorado } & $\mathrm{N}$ & $\%$ \\
\hline \multicolumn{3}{|l|}{ Saúde Coletiva/Saúde Pública/Medicina Preventiva } & 74 & 29,14 \\
\hline \multicolumn{3}{|l|}{ Economia } & 71 & 27,96 \\
\hline \multicolumn{3}{|l|}{ Ciências Médicas } & 25 & 9,84 \\
\hline \multicolumn{3}{|l|}{ Epidemiologia } & 12 & 4,72 \\
\hline \multicolumn{3}{|l|}{ Administração } & 9 & 3,54 \\
\hline \multicolumn{3}{|l|}{ Engenharia } & 7 & 2,76 \\
\hline \multicolumn{3}{|l|}{ Ciências Farmacêuticas } & 6 & 2,36 \\
\hline \multicolumn{3}{|l|}{ Enfermagem } & 6 & 2,36 \\
\hline \multicolumn{3}{|l|}{ Ciências Sociais } & 5 & 1,97 \\
\hline \multicolumn{3}{|l|}{ Políticas Públicas } & 4 & 1,57 \\
\hline \multicolumn{3}{|l|}{ Outros ${ }^{\star}$} & 35 & 13,78 \\
\hline \multicolumn{3}{|l|}{ Total } & 254 & 100,00 \\
\hline \multirow[t]{2}{*}{ Área do Doutorado } & $\begin{array}{l}\text { a 'An } \\
\text { tivid }\end{array}$ & $\begin{array}{l}\text { liação } \\
\text { iência' }\end{array}$ & $\begin{array}{r}\text { Produção de ar } \\
\text { em 'Ec }\end{array}$ & $\begin{array}{l}\text { entíficos } \\
\text { Política' }\end{array}$ \\
\hline & $\mathbf{N}$ & $\%$ & $\mathrm{~N}$ & $\%$ \\
\hline Saúde Coletiva/Saúde Pública/Medicina Preventiva & 34 & 31,48 & 3 & 11,54 \\
\hline Ciências Médicas & 20 & 18,52 & 0 & 0,00 \\
\hline Economia & 16 & 14,81 & 20 & 76,91 \\
\hline Epidemiologia & 10 & 9,26 & 0 & 0,00 \\
\hline Ciências Farmacêuticas & 6 & 5,56 & 0 & 0,00 \\
\hline Enfermagem & 5 & 4,63 & 0 & 0,00 \\
\hline Administração & 3 & 2,78 & 1 & 3,85 \\
\hline Ciências Sociais & 0 & 0,00 & 1 & 3,85 \\
\hline
\end{tabular}




\begin{tabular}{lrrrr} 
Tabela 3. (cont.) & & & \\
\hline Estudos da América Latina & 0 & 0,00 & 1 & 3,85 \\
Outros $^{\star \star}$ & 14 & 12,96 & 0 & 0,00 \\
Total $^{*}$ & 108 & 100,00 & 26 & 100,00 \\
\hline
\end{tabular}

Fonte: Elaboração própria baseada em dados do Currículo Lattes, 2018.

*Incluem área de doutorado: Ciências da Saúde, Demografia, Nutrição, Política Social, Inovação Terapêutica, Integração da América, Psicologia, Arquitetura e Urbanismo, Avaliação Tecnológica, Bioética, Biotecnologia, Ciências, Ciências de Materiais, Ciências Visuais, Desenvolvimento Rural, Educação, Estudos da América Latina, Geografia, Gestão e Informática da Saúde, História, Population Health, Processos de Desenvolvimento Humano e Saúde, Química e Tecnologia Nuclear. ${ }^{\star \star}$ Incluem: Demografia, Tecnologia Nuclear, Nutrição, Química, Population Health, Avaliação Tecnológica, Integração da América, Gestão e Informática em Saúde, Política Públicas, Engenharia e Ciências.

Após essa primeira aproximação, que delimitou os pesquisadores doutores, a familiaridade com as análises da economia política, graduações e área de doutorado, realizou-se um mapeamento da produção de artigos publicados em periódicos científicos nas seguintes subáreas: 'financiamento', 'política de saúde', 'gestão em saúde' e 'análise/avaliação de custo, efetividade e eficiência' (tabela 4).

Foi identificado que $20,47 \%$ (52) dos pesquisadores doutores produzem na subárea do 'financiamento'; 13,39\% (34), na subárea de 'política de saúde'; 20,87\% (53), na subárea de 'gestão em saúde'; e 42,52\% (108), na subárea de 'análise/avaliação de custo, efetividade e eficiência' - estas duas últimas mais associadas à perspectiva convencional/neoclássica. Além disso, estratificando-se a produção de 'análise/ avaliação de custo, efetividade e eficiência' pela área de doutorado, é possível notar uma predisposição por autores provenientes de áreas da saúde, principalmente, saúde coletiva/ saúde pública/medicina preventiva, $31,48 \%$ (34), e ciências médicas, $18,52 \%$ (20), o que contrasta com uma menor presença relativa de pesquisadores doutores provenientes da área de economia (tabela 3).

Tabela 4. Principais termos relativos às subáreas de pesquisa em economia da saúde e a presença de produção de artigos científicos em 'economia política' e 'economia política da saúde' identificadas nos Currículos Lattes dos pesquisadores recuperados a partir do descritor 'economia da saúde'. Brasil, 2018

\begin{tabular}{lrr}
\hline Financiamento & N & $\%$ \\
\hline Não foi encontrada a subárea 'financiamento' & 202 & 79,53 \\
Foi encontrada a subárea 'financiamento' & 52 & 20,47 \\
Total & 254 & 100,00 \\
\hline Política de saúde & $\mathbf{N}$ & $\%$ \\
\hline Não foi encontrada a subárea 'política de saúde' & 220 & 86,61 \\
Foi encontrada a subárea 'política de saúde' & 254 & 13,39 \\
Total & $\mathbf{N}$ & 100,00 \\
\hline Gestão em saúde & 201 & 79,13 \\
\hline Não foi encontrada a subárea 'gestão em saúde' & 53 & 20,87 \\
Foi encontrada a subárea 'gestão em saúde' & 254 & 100,00 \\
\hline Total & & $\%$
\end{tabular}


Tabela 4. (cont.)

\begin{tabular}{lrr}
\hline Análise/Avaliação de Custo, Efetividade e Eficiência & N & \% \\
\hline Não foi encontrada a subárea 'análise/avaliação de custos, efetividade e eficiência' & 146 & 57,48 \\
Foi encontrada a subárea 'análise/avaliação de custos, efetividade e eficiência' & 108 & 42,52 \\
Total & 254 & 100,00 \\
\hline Produção de artigos científicos em 'Economia Política' & $\mathbf{N}$ & $\%$ \\
\hline Não apresenta produção & 226 & 88,98 \\
Apresenta produção & 254 & 11,02 \\
Total & $\mathbf{N}$ & 100,00 \\
\hline Produção de artigos científicos em 'Economia Política da Saúde' & 248 & 97,64 \\
\hline Não apresenta produção & 6 & 2,36 \\
Apresenta produção & 254 & 100,00 \\
\hline Total &
\end{tabular}

Fonte: Elaboração própria baseada em dados do Currículo Lattes, 2018

Agora, no intuito de descrever os níveis de aproximação dos 'economistas da saúde' com a 'economia política', além da primeira análise categórica (tabela 1), empregou-se uma análise de suas produções de artigos publicados em periódicos científicos com filiação à 'economia política' - sem discernimento em qual setor que é aplicada - e 'economia política da saúde'. Esse filtro na análise demonstrou que apenas $11,02 \%$ (28) dos pesquisadores doutores filiam suas produções à 'economia política' e que, residualmente, $2,36 \%$ (6) analisam a 'saúde' por este prisma (tabela 4). Além disso, esses pesquisadores doutores que filiam suas análises aos paradigmas abarcados pela economia política são, majoritariamente, advindos de doutorados na área da economia, 76,91\% (20), e com a área de saúde coletiva/saúde pública/ medicina preventiva, $11,54 \%$ (3), assumindo um papel minoritário (tabela 3 ).

Além dessa caracterização em produção de artigos e área de doutorado proveniente, foi preciso estratificar as áreas temáticas que os 'economistas políticos' preferencialmente se debruçam. Com essa intenção, a análise foi norteada pelos níveis de aproximação da economia política, em suas modalidades estudadas, nas diversas áreas temáticas. Dessa maneira, as subáreas de 'financiamento' e 'gestão em saúde' foram estratificadas em três modalidades em relação à economia política: a) apresentavam o termo 'economia política' nos currículos, b) produção de artigos em 'economia política' e c) produção de artigos em 'economia política da saúde'. Nessas subáreas, foi possível observar uma tendência ascendente do 'financiamento' como subárea de maior aproximação com a produção em economia política, sendo, respectivamente: $28,95 \%, 28,57 \%$ e $55,56 \%$. Já para a subárea de 'gestão em saúde', identificou-se uma tendência declinante: $22,37 \%, 17,86 \%$ e $11,11 \%$ respectivamente (tabela 5).

Nas subáreas de 'política de saúde' e 'análise/avaliação de custo, efetividade e eficiência', foi priorizada a estratificação em apenas duas modalidades: a) apresentavam o termo 'economia política' nos currículos e b) produção de artigos em 'economia política'. Ainda, foi possível observar que, na subárea 'política de saúde', a tendência é ascendente, pois é verificada a maior proximidade com a produção em economia política, sendo: $19,74 \%$ e $21,43 \%$ respectivamente. Já em 'análise/ avaliação de custo, efetividade e eficiência' a tendência é declinante, sendo $23,68 \%$ e $10,76 \%$ respectivamente (tabela 5). 
Tabela 5. Distribuição descritiva da produção científica de artigos nas subáreas de 'financiamento' e 'gestão em saúde' a partir de 'economia política' e produção científica de artigos em 'economia política - Produção' e 'economia política - produção em saúde' e a estratificação da produção científica de artigos nas subáreas de 'política de saúde' e 'análise/avaliação de custo, efetividade e eficiência' a partir de 'economia política' e produção científica de artigos em 'economia política - produção'. Brasil, 2018

\begin{tabular}{|c|c|c|}
\hline & Financiamento & Gestão em saúde \\
\hline \multirow[t]{2}{*}{ Economia Política } & Foi encontrada a subárea & Foi encontrada a subárea 'gestão em saúde' \\
\hline & 'financiamento' & \\
\hline Não apresentavam o termo 'economia política' nos seus currículos & $16,85 \%$ & $20,22 \%$ \\
\hline Apresentavam o termo 'economia política' nos seus currículos & $28,95 \%$ & $22,37 \%$ \\
\hline \multicolumn{3}{|l|}{ Economia Política - Produção } \\
\hline Não apresenta produção & $19,47 \%$ & $21,24 \%$ \\
\hline Apresenta produção & $28,57 \%$ & $17,86 \%$ \\
\hline \multicolumn{3}{|l|}{ Economia Política - Produção em Saúde } \\
\hline Não apresenta produção & $19,18 \%$ & $21,22 \%$ \\
\hline \multirow[t]{2}{*}{ Apresenta produção } & $55,56 \%$ & $11,11 \%$ \\
\hline & Política de Saúde & $\begin{array}{r}\text { Análise/Avaliação de Custo, } \\
\text { Efetividade e Eficiência }\end{array}$ \\
\hline Economia Política & $\begin{array}{r}\text { Foi encontrada a subárea } \\
\text { 'política de saúde' }\end{array}$ & $\begin{array}{r}\text { Foi encontrada a subárea 'análise/avaliação de } \\
\text { custos, efetividade e eficiência' }\end{array}$ \\
\hline Não apresentavam o termo 'economia política' nos seus currículos & $10,67 \%$ & $50,56 \%$ \\
\hline Apresentavam o termo 'economia política' nos seus currículos & $19,74 \%$ & $23,68 \%$ \\
\hline \multicolumn{3}{|l|}{ Economia Política - Produção } \\
\hline Não apresenta produção & $12,39 \%$ & $46,46 \%$ \\
\hline Apresenta produção & $21,43 \%$ & $10,76 \%$ \\
\hline
\end{tabular}

Fonte: Elaboração própria baseada em dados do Currículo Lattes, 2018.

Outro resultado importante, além dessas tendências ascendentes e declinantes, é a predileção pelos pesquisadores doutores que produzem em economia política pelas subáreas de 'financiamento' $28,57 \%$ e 'política de saúde' 21,43\% (tabela 5). Desse modo, é ressaltada uma inversão de preferência com relação ao total do campo da economia da saúde, que produz, preponderantemente, em 'gestão em saúde' 20,87\% e 'análise/avaliação de custo, efetividade e eficiência' $42,52 \%$ (tabela 4 ).

\section{Discussão}

Com o intuito de sustentar a argumentação deste artigo, é prudente um mínimo de exposição sobre as bases e atuações da escola de pensamento neoclássico na área da saúde, visto que a interpretação dos resultados depende diretamente do entendimento da centralidade da gestão e análise de custo e benefício na disciplina da microeconomia.

Segundo Braga e de Paula ${ }^{22}$, a predileção do pensamento neoclássico pela gestão e análise de custo deve-se pela restrição do escopo da economia, em termos de objeto, e em somente trabalhar com categorias 'operacionalizáveis'. Desse modo, a economia neoclássica direciona suas análises somente para a indústria da atenção à saúde, derivando desta a responsabilidade pelos níveis de saúde da população.

Ora, por mais que a indústria de atenção à saúde tenha algum mérito na melhoria das condições de saúde das populações, seu impacto em escala social é reduzido quando 
comparada ao modo de produção social que conduz o curso da vida ${ }^{23}$. Nesse sentido, Braga e de Paula não exageram quando dizem que a saúde na perspectiva neoclássica reduz quase tudo à expressão 'contábil', sendo a saúde correspondente à capacidade produtiva da sociedade em questão. De maneira prática, a análise neoclássica volta-se principalmente para a

operacionalização de unidades de atenção à saúde. Na verdade, são utilizadas aqui técnicas de administração e gerência, válidas para quaisquer unidades produtivas, buscando a maximização de lucros - ou benefícios - ou a diminuição dos prejuízos - custos 22(59).

A partir da impossibilidade da análise neoclássica em aproximar-se do objeto em questão - a saúde - por suas opções teórico-metodológicas, dissocia a saúde da totalidade das relações sociais, autonomizando a economia de outras disciplinas. Em que pese à relevância dessa tarefa no desenvolvimento das ciências de maneira geral ${ }^{24,25}$, o problema reside na falta de reconexão do conhecimento produzido com o todo social. Por esse recorte, há a predominância de uma falsa autonomia do econômico diante do todo social.

Em certa maneira, essa autonomização do 'econômico' é o pressuposto epistêmico da vertente neoclássica que dialoga com as especializações dos objetos em saúde. Assim, poderíamos afirmar, com algum grau de certeza, que essa autoimposição das análises estritamente microeconômicas, das quais a economia da saúde é herdeira, corrobora o reducionismo linear preponderante nas análises da epidemiologia convencional ${ }^{18}$.

Nessa esteira, há uma associação (muitas vezes meramente formal) entre a utilização dos serviços de saúde e os níveis de saúde dessa população. Porém, essa retórica cumpre uma agenda política muito clara, como alerta Braga e Paula: "o problema da saúde vai reduzir-se ao problema da atenção à saúde"22(62) com implicações bastante controversas sobre o que vem a ser sustentabilidade por exemplo.
Essa passa a ser considerada como a 'economia do custo' e, portanto, a 'redução do acesso' em termos da análise empreendida; isso pode ser constatado pela clara filiação da produção da economia da saúde às subáreas de 'gestão em saúde' e 'análise/avaliação de custo, efetividade e eficiência'.

Devido à relevância das subáreas 'gestão em saúde' e 'análise/avaliação de custo, efetividade e eficiência' na produção de artigos científicos dos pesquisadores doutores considerados 'economistas da saúde', é possível demonstrar que, no Brasil, os ditames desse campo são dominados pelo paradigma econômico hegemônico: o pensamento neoclássico. Além disso, a compreensão que esses pesquisadores doutores, orientados por essa lógica, são provenientes de doutorados de áreas da saúde - especialmente saúde coletiva/saúde pública/medicina preventiva - sugere a subserviência da formação em saúde à agenda política anteriormente citada.

A lógica da valorização do capital e, por consequência, seus efeitos deletérios não são discutidos na perspectiva neoclássica, o que prejudica o refinamento analítico a respeito das condições de sustentabilidade dos sistemas de saúde. Essa perspectiva reduz as análises dos condicionantes materiais (econômicos) dos níveis de saúde apenas ao problema da assistência à saúde e impede o tratamento à consolidação de uma saúde pública universal.

No eixo da 'economia política', os achados relevam que seus pesquisadores doutores estão residualmente presentes no campo da economia da saúde e concentram suas produções científicas basicamente nas subáreas de 'financiamento' e 'política de saúde'. Essa tendência torna-se mais intensa com a aproximação, gradativa, das subáreas com a produção de artigos científicos em 'economia política' e, especificamente, em 'economia política da saúde'. De maneira curiosa, contrariamente ao campo da economia da saúde, os 'economistas políticos' são provenientes, em sua maioria, de doutorados de áreas da economia. 
A partir da constatação dessa evidente cisão entre as áreas da economia da saúde e da economia política, é exposta uma realidade histórica específica do capitalismo nessas produções: a separação (ainda que formal) entre o político e o econômico ${ }^{26}$. Essa análise fragmentada da realidade não leva em conta que o econômico - a produção de mercadorias e a sua realização no mercado - é essencialmente político, ou seja, as relações sociais que possibilitam a produção capitalista de mercadorias derivam da clivagem desigual de poder entre a classe proprietária dos meios de produção e aqueles que nada possuem além de sua força de trabalho.

O modo de produção capitalista, portanto, para assegurar sua sobrevivência, utiliza-se, de forma aparente, da separação entre a esfera econômica e de seu conteúdo político. Para uma análise marxista, a construção de um pensamento que se baseia nessa separação permite a domesticação da luta de classes e a mistificação da consciência dos trabalhadores. Em outras palavras, o pensamento neoclássico atende aos interesses da produção mercantil, cumprindo esse papel ideológico ao alinhar-se à predominância positivista característica do discurso científico do setor saúde. No entanto, a economia política crítica advoga que o conhecimento produzido deva levar à consciência aos trabalhadores e a superar a alienação, reconhecendo-os como sujeito histórico da transformação social27, evitando, portanto, a autonomização absoluta das categorias econômicas e políticas.

No setor saúde, esse processo de mistificação é hegemonizado pelo predomínio da técnica sobre a política, o que se traduz, em termos políticos, na defesa ideológica do gerencialismo ${ }^{\mathbf{2 8}}$. Nesse cenário, o desenvolvimento das 'modernas' técnicas de gestão não é contextualizado a partir da necessidade do avanço das forças produtivas, à medida que não se enfrenta a inserção dependente no mercado mundial. Pelo contrário, essas técnicas gerenciais são implementadas como uma contratendência ao declínio da taxa de lucro do capital ${ }^{29}$, com a finalidade de intensificação da força de trabalho e retomada da superexploração - exploração do trabalho orientada à transferência de parcela do mais valor no sentido da periferia para o centro do capitalismo ${ }^{30}$.

Não é por acaso é que os estudos dos economistas da saúde neoclássicos têm sua predileção pela área de gestão em saúde e análise de custo-efetividade. Esse conhecimento, em última instância, tem servido para fundamentar cientificamente o gerencialismo no seio do setor saúde, com a utilização exacerbada da metrificação dos resultados, levando a uma visão 'contábil' dos níveis de produção de serviços de saúde. É pertinente lembrar que o gerencialismo na saúde tem como função precípua a reorientação da atenção à saúde aos ditames da reprodução ampliada do capital, por dentro do aparelho do Estado como no caso brasileiro ${ }^{29}$, sendo essa reprodução contraproducente ao estudo dos sistemas de saúde ditos universais.

No que tange à análise de custo-efetividade, essa separação entre o político e o econômico é ainda mais funcional ao capital. Essa modalidade de análise, estritamente baseada na microeconomia, ignora a problemática mais ampla da determinação da dependência sobre o aparato industrial-tecnológico e a deterioração dos termos de troca entre países capitalistas de desenvolvimento desigual ${ }^{9}$. Ao se restringir à mera avaliação contábil, essa análise de custo-efetividade revela somente a aparência do fenômeno. Logo, para o setor saúde, o uso irrestrito dessa modalidade de análise leva à compreensão distorcida dos reais entraves para a implementação tecnológica, em característica universais, no SUS.

Esses entraves, revelados dentro de uma perspectiva totalizante, são derivados da capacidade reduzida de financiamento da seguridade social e do sequestro do fundo público pelo capital financeiro ${ }^{31}$ - marcadamente exemplificados pela Desvinculação de Receitas da União (DRU) e pela Emenda Constitucional 95/2016 (EC 95) ${ }^{29}$. Tais entraves podem ser compreendidos pelo fato de termos, no Brasil, a implantação forçosa de um Estado social ${ }^{32}$ anacrônico quando comparado aos países de 
capitalismo avançado. A rigor, é perceptível o profundo descompasso histórico brasileiro para com o movimento do capital, especialmente na implementação do SUS durante a hegemonia do neoliberalismo e no auge do pensamento neoclássico. Portanto, a análise de custo-efetividade, no ambiente de financiamento restrito e sequestro do fundo público, contribui significativamente para o desmonte e para a focalização das políticas sociais, e não para sua universalização.

Assim, considerar a sustentabilidade dos sistemas de saúde, nos países de capitalismo dependente, e, em especial, no caso brasileiro, requer que a forma política ${ }^{33}$ da sociabilidade capitalista seja incorporada na análise dos economistas da saúde, rumo a uma economia política crítica desse setor. Dessa maneira, entende-se que, nessa sociabilidade de escala global, a sustentabilidade real dos sistemas de saúde depende muito mais da consciência e ação política organizada da classe trabalhadora do que necessariamente do foco na relação de agentes econômicos isolados.

Por mais bem intencionados que os economistas da saúde sejam, é mister assumir que o conhecimento e sua produção são feitos por sujeitos sociais inseridos na ordem do capital, portanto, se esses pesquisadores doutores não se questionam insistentemente a quais interesses o conhecimento que produzem estão subsumidos, é razoável pensar que formam um exército ideológico reprodutor da ordem. Nesse sentido, é até possível admitir que poucos são aqueles que questionam a episteme em que se assentam, preferindo reproduzir a ideologia dominante que se entranha na produção cientifica na área da economia da saúde do que assumir a defesa da saúde ainda enquanto direito e, nem sequer, como emancipação humana.

Contudo, para assegurar uma reflexão acerca da sustentabilidade necessária para o sistema de saúde no Brasil, entendemos ser necessário questionar o conhecimento produzido e seus marcos paradigmáticos. Afinal, no enfretamento dessas questões, como, por exemplo, da inserção de nosso país na divisão internacional do trabalho, as interpretações elaboradas neste estudo tornam mais evidentes o aspecto eminentemente político da saúde. Como bem nos relembra Ferrara ${ }^{34}$, 'a saúde é a solução do conflito', e não de um conflito qualquer, mas, sim, do conflito capital-trabalho e que nessa ordem social, infelizmente, não se pode esquivar.

\section{Considerações finais}

Ante o exposto, este estudo demonstrou que a parcela de pesquisadores doutores que se filiam à 'economia política da saúde' no Brasil é praticamente inexpressiva quando considerado o total daqueles pesquisadores doutores que se dedicam à economia da saúde, de abordagem neoclássica.

A produção científica sobre 'economia da saúde' no Brasil tem-se mostrado mais afiliada ao pensamento neoclássico; por sua vez, viu-se que a abordagem sobre a 'economia política' no setor saúde é rarefeita. Foi possível perceber que a produção dos economistas da saúde tem-se adequado muito mais a uma abordagem restrita à dinâmica da lógica capitalista do que uma abordagem totalizante. Desse modo, pode-se dizer que essa perspectiva teórico-metodológica pode dificultar a apreensão da saúde enquanto fenômeno social complexo, sendo, portanto, incompatível como o marco teórico fundacional da saúde coletiva, circunscrevendo-se apenas à aparência contábil e, porque não lembrar, contribuindo para a reificação e fetichização das necessidades radicais, das quais a saúde é uma delas.

Outro aspecto importante identificado no estudo refere-se à maior vinculação do núcleo formativo em saúde (Programas de Doutorado em Saúde Coletiva, Saúde Pública e Medicina Preventiva) ao pensamento neoclássico, quando se dedicam ao estudo da 'economia da saúde'. Um efeito disso tem sido a insistência das análises de custo-efetividade que reduzem o econômico à unidade produtiva e 
as dissociam da dinâmica do capitalismo. Logo, seus resultados, assentados nesse pensamento, findam por contribuir mais para o desmonte e focalização das políticas sociais do que para sua universalização.

Nesse contexto, ao refletir sobre a sustentabilidade do sistema de saúde, reiteramos ser fundamental considerar a contribuição da economia política crítica nas análises do campo da 'economia da saúde'. Somente assim o direito à saúde passa a se constituir tema principal nas análises, e seus constrangimentos podem ser mais bem compreendidos pela própria natureza do modo de produção capitalista em sua fase contemporânea.

\section{Colaboradores}

Alves DFA (0000-0003-0080-1919)*, Carnut L (0000-0001-6415-6977)* e Mendes A (00000002-5632-4333)* contribuíram igualmente na elaboração do manuscrito.

\section{Referências}

1. Dardot P, Laval C. A nova razão do mundo: ensaios sobre a sociedade neoliberal. São Paulo: Boitempo; 2016.

2. Mendes A. Brazilian public health in the context of a State crisis or a crisis of capitalism? Saude soc. [internet]. 2015 [acesso em 2019 mar 31]; 24(supl1):66-81. Available from: http://www.scielo.br/scielo.php?script=sci_arttext\&pid=S0104$-12902015000500066 \& \operatorname{lng}=\mathrm{en}$.

3. Demier F. Depois do golpe: a dialética da democracia blindada no Brasil. Rio de Janeiro: Mauad; 2017.

4. Niven PR. Balanced scoredcard passo-a-passo: elevando o desempenho e mantendo resultados. Rio de Janeiro: Qualitymark; 2005.

*Orcid (Open Researcher and Contributor ID).
5. Kaplan RS, Norton DP. A estratégia em ação: balanced scorecard. 13. ed. Rio de Janeiro: Campus; 1997.
6. Carnut L. Crítica a modelos de avaliação de desempenho de sistemas de saúde [tese]. São Paulo: Universidade São Paulo; 2015. 146 p.

7. Lessa S, Tonet I. Introdução à filosofia de Marx. 2. ed. São Paulo: Expressão Popular; 2011.

8. Marx K. O capital: crítica da economia política: livro 1: o processo de produção do capital. 2. ed. São Paulo: Boitempo; 2017.

9. Marini RM. Dialética da dependência. In: Stedile JP, Traspadini R, organizadores. Ruy Mauro Marini: vida e obra. 2. ed. São Paulo: Expressão Popular; 2011. p. $131-172$.

10. Netto JP, Braz M. O imperialismo. In: Netto J, Braz M. Economia Política: uma introdução crítica. 8. ed. São Paulo: Cortez; 2012. p. 181-222. 
11. Ianni O. A Idéia de Brasil Moderno. São Paulo: Editora Brasiliense; 1992.

12. Oliveira F. Crítica à razão dualista: o ornitorrinco. São Paulo: Boitempo; 2013.

13. Fernandes F. Capitalismo dependente e classes sociais na América Latina. São Paulo: Globo; 2009.

14. Sampaio Jr PA. Desenvolvimentismo e neodesenvolvimentismo: tragédia e farsa. Ser soc soc [internet]. 2012 [acesso em 2019 mar 31]; 112:672-688. Disponível em: http://www.scielo.br/pdf/sssoc/n112/04.pdf.

15. Mendes-Gonçalves RB. Práticas de saúde: processos de trabalho e necessidades. São Paulo: Secretaria Municipal de Saúde; 1992.

16. Márkus G. Marxismo e Antropologia: o conceito de 'essência humana' na filosofia de Marx. São Paulo: Expressão Popular; 2015.

17. Pachukanis EB. Teoria geral do direito e marxismo. São Paulo: Boitempo; 2017.

18. Breilh J. Epidemiologia crítica: ciência emancipadora e interculturalidade. Rio de Janeiro: Fiocruz; 2006.

19. Mendes A. Os impasses dos direitos sociais trabalhistas e do financiamento da seguridade social e da saúde brasileira no capitalismo contemporâneo em crise. In: Souza H, Mendes A, organizadores. Trabalho e saúde no capitalismo contemporâneo: enfermagem em foco. Rio de Janeiro: Doc Content; 2016. p. 42-74.

20. Mendes A, Ianni AMZ, Marques MCC, et al. A contribuição do pensamento da saúde coletiva à economia política da saúde. Saude soc [internet]. 2017 [acesso em 2019 mar 31]; 26(4):841-860. Disponível em: http://www.scielo.br/scielo.php?script=sci_ arttext\&pid=S0104-12902017000400841\&lng=pt.

21. Brasil. Ministério da Saúde. A produção de conhecimento em Economia da Saúde: uma perspectiva bibliográfica (2004-2012). Brasília, DF: Ministério da Saúde; 2013.
22. Braga JC, de Paula SG. Capitalismo e pensamento econômico: a questão da saúde. In: Braga JC, de Paula SG. Saúde e previdência: estudos de política social. 3. ed. São Paulo: Hucitec; 2018. p. 23-83.

23. Mckeown T, Lowe CR. Introducción a la Medicina Social. México: Siglo XXI; 1989.

24. Kuhn TS. A estrutura das revoluções científicas. 13. ed. São Paulo: Perspectiva; 2018.

25. Prado EFS. Complexidade e Práxis. São Paulo: Plêiade; 2011.

26. Wood EM. A separação entre o "econômico" e o "político" no capitalismo. In: Wood ME. Democracia contra capitalismo: a renovação do materialismo histórico. São Paulo: Boitempo; 2011. p. 27-50.

27. Iasi ML. Reflexão sobre o processo de consciência. In: Iasi ML. Ensaios sobre a consciência e emancipação. 2. ed. São Paulo: Expressão Popular; 2011. p. 11-46.

28. Carnut L, Narvai PC. Avaliação de desempenho de sistemas de saúde e gerencialismo na gestão pública brasileira. Saude soc [internet]. 2016 [acesso em 2019 mar 31]; 25(2):290-305. Disponível em: http://www. scielo.br/scielo.php?script=sci_arttext\&pid=S0104$-12902016000200290 \& \operatorname{lng}=\mathrm{pt}$.

29. Mendes A, Carnut L. Capitalismo contemporâneo em crise e sua forma política: o subfinanciamento e o gerencialismo na saúde pública brasileira. Saude soc. [internet]. 2018 [acesso em 2019 mar 31]; 27(4):1105-1119. Disponível em: http://www.scielo.br/scielo.php?script=sci_arttext\&pid=S0104$-12902018000401105 \& \operatorname{lng}=$ pt.

30. Traspadini R. Dependência e luta de classes na América Latina. Argumentum [internet]. 2014 [acesso em 2019 mar 31]; 6(2):29-43. Disponível em: http://periodicos.ufes.br/argumentum/article/view/8504/6208.

31. Behring ER, Boschetti I. Política social: fundamentos e história. 9. ed. São Paulo: Cortez; 2011. 
32. Boschetti I. Assistência social e trabalho no capitalismo. São Paulo: Cortez; 2016.

33. Codato A. O espaço político segundo Marx. Crítica Marxista [internet]. 2011 [acesso em 2019 mar 31]; 32:33-56. Disponível em: https://www.ifch.unicamp. br/criticamarxista/arquivos_biblioteca/artigo232artigo2.pdf.
34. Ferrara FA. Teoría social y salud. Bueno Aires: Catalogos; 1985.

Recebido em 09/04/2019

Aprovado em 10/10/2019

Conflito de interesses: inexistente

Suporte financeiro: não houve 